\title{
STABILITY ANALYSIS OF THE SINGLE-LAYER DOME IN PROBABILISTIC DESCRIPTION BY THE MONTE CARLO METHOD ${ }^{1}$
}

\author{
PaweŁ Zabojszcza, Urszula Radoń \\ Kielce University of Technology, Faculty of Civil Engineering and Architecture, Kielce, Poland \\ e-mail: pawelzab@tu.kielce.pl; zmbur@tu.kielce.pl
}

\begin{abstract}
The paper shows the application of the Monte Carlo method to the stability analysis of a single-layer shallow $(h / d=0.04)$ dome modelled with frame elements. Structures of this type are characterized by strong nonlinearity, consequently, they are extremely susceptible to stability loss resulting from the node snap-through. It is necessary to perform a nonlinear stability analysis that allows determination of limit points related to that mode of stability failure. This paper shows that with the reliability analysis methods, it is possible to trace the failure probability level while moving along the load-displacement path towards the limit point.
\end{abstract}

Keywords: stability, frame structure, single-layer domes, reliability index, Monte Carlo method

\section{Introduction}

Bar coverings are used as bearing structures in buildings of various purposes. The scope of their application is very wide and covers many fields of engineering. Bar coverings function as main parts of supporting structures in halls, shopping malls, station halls, sports buildings, swimming pools, theatres, concert halls, churches and similar facilities. The axes of the bars form a specific spatial geometric grid. Regular placement of mesh nodes on a given surface is often found. The surfaces used can most often be described by simple mathematical expressions. The surface shape can be selected in such a way that for the configuration of given geometric constraints and for dominant loads, it maintains specific stiffness and stability (low sensitivity to local snapping).

The optimal shape of the base surface corresponds to a membrane state in which only tensile forces without bending and with low compression are present. The correct selection of base surfaces is a prerequisite for applying a single-layer bar covering. If bending occurs in the structure, it is necessary to use rigid edge girders, or double-layer meshes. Structure analysis and connection details vary depending on the number of layers used in the mesh. A single-layer covering is most often constructed using rigid nodes, while multi-layer coatings employ pinned joints.

Due to the presence of rigid joints in single-layer bar coverings, the occurrence of node snapping is significantly prevented. The use of this type of connections substantially increases the rigidity of the structure, which is important in the event of dynamic variable loads (wind). As regards a single-layer covering, it is possible to use pinned joints, however, it is required to fully examine the phenomenon of nodal snap (global stability), natural frequency and torsion resistance of the mesh covering (Kacprzyk and Pawłowska, 1999; Chodor, http, 2019).

In this paper, a single-layer steel bar dome is considered, i.e. the covering described on the sphere erected on a round base. Domes belong to the oldest known and widely used large-span coverings. In practice, 5 types of domes are most often employed. They include Schwedler,

\footnotetext{
${ }^{1}$ The results contained in this paper were presented at the 4th Polish Congress of Mechanics, 23rd International Conference on Computer Methods in Mechanics.
} 
Lamella, ribbed, and geodetic domes. The fifth type are domes with isosceles triangular mesh in each layer.

The key advantages these structures offer are low self-weight, relatively high load capacity, and repeatability of the elements, especially in the case of small spans. In the design of this type of structure, the phenomena associated with their stability may be decisive (Marcinowski, 2017; Waszczyszyn et al., 1994; Thompson and Hunt, 1973; Kleiber, 1982; Zabojszcza and Radoń, 2019a).

\section{Methods of structural analysis}

In the traditional design process, internal forces are calculated using various methods of static and stability analysis. Depending on whether the distribution of internal forces is determined using the range of linear-elastic behaviour of bars and nodes of the system, or the possibility of plastic redistribution of internal forces in the elements is used, two basic methods are distinguished: elastic and plastic design. The elastic design (design due to reaching the limit state in the most stressed section of the element, or the most stressed element of the structure) is based on assuming a constant stiffness of the elements with a cross-section of classes 1-4. The elastic design is applicable to structures composed of bars of different cross-section classes and nodes with different rotational capabilities. The plastic design is connected with such a design situation in which internal forces in the system elements and stability assessment are determined taking into account the plastic reserve of redistribution of moments in bar cross-sections and system nodes. In the elastic and plastic design of steel bar structures, bar systems can be distinguished utilizing three basic groups of structural analysis methods. The latter include the following: first order static analysis, second order static analysis and advanced analysis (second order analysis that accounts for imperfections).

The first group are methods using the first-order, geometrically linear analysis such as: linear-elastic methods - LA (Linear Analysis) or inelastic plastic joints - MNA (Materially Nonlinear Analysis). Static analysis is supported by bifurcation analysis of buckling in the plane of the system in order to determine buckling length coefficients of its compressed elements: LBA (Linear Buckling Analysis) in the case of the elastic design, MNBA (Materially Nonlinear Buckling Analysis) in the case of design accounting for plastic reserves. The elastic design takes into consideration the buckling mode of the system, which corresponds to the lowest buckling load value, called the critical load in the sense of the elastic stability theory of the initial system. According to PN-EN 1993-1-1/5.2.1(3), the first-order analysis can be used if the increase in internal forces or moments, or any other change in the behaviour of the structure due to deformation, can be disregarded. It is assumed that in the case of elastic analysis, this happens if the criterion is met $\alpha_{c r} \geqslant 10$, where $\alpha_{c r}$ is the critical load multiplier in relation to design loads.

Self-stable structures and susceptible bracing which do not meet this condition, depending on the design method, can be considered as tilted systems with elements in which forces are calculated taking into account second order effects.

If $\alpha_{c r}<3.0$, the second order analysis (GNA) is used in the elastic design, and if $3.0<\alpha_{c r}<10.0$ - the approximate second order elastic analysis (PDNA).

The PDNA analysis allows for an approximate consideration of the stability of the $P$-Delta effect and, hence, an approximate assessment of the internal forces taking into account the global second-order tilting effects. PDNA analysis methods can be used for systems in which the compression elements have a relatively small slenderness and/or longitudinal forces of low value. Then, the $P$-delta effect on the flexural rigidity of compression bars and the distribution of internal forces can be disregarded. 
Accurate methods of the GNA group use the second-order analysis which takes into account $P$-Delta and $P$-delta stability effects. The support of static analysis by buckling analysis is not required in this case due to the fact that the close second order theory is a natural extension of the theory of stresses to the case of bending with participation of longitudinal forces. Buckling lengths, used to check the criteria of bearing capacity of elements, are assumed equal to the lengths of bars between nodes. The elastic analysis of GNA is carried out incrementally following the load history, or iteratively by the secant method for the level of the design load.

The last group of methods are advanced analyses, i.e. second-order analysis, in which global and local imperfections are taken into account at the stage of structural analysis. In the elastic design, when the second-order analysis is used with imperfections GNIA (Geometric Nonlinear with Imperfection Analysis), the limit load is identified by reaching the load capacity of the most stressed section of the bar or node. In the design practice, the GNIA analysis can be performed in one calculation step for longitudinal forces estimated or determined from a linear analysis of LA in relation to design loads (Giżejowski and Ziółko, 2010; PN-EN 1993-1-1).

The purpose of this paper is to estimate the influence of imperfections on the reliability of a single-layer steel dome. The analysis is based on linear relations between stresses and strains. These structures are subjected to large displacement gradients and are susceptible to stability loss from the condition of node snapping. When designing such structures, local buckling of individual bars is also possible. However, this is not a mode of stability loss that determines the load-bearing capacity of the structure. These structures are extremely sensitive to even slight changes in materials parameters or geometry. Therefore, the imperfection description is very important for the correct design of such structures. In this paper, the probabilistic approach is used to describe imperfection (Zabojszcza and Radon, 2019b; Kato et al., 1998; Liu et al., 2016; Luca et al., 2016). The values of the reliability index are calculated with the Monte Carlo method (Mochocki and Radoń, 2019; Rubinstein, 1981).

\section{Reliability analysis - the Monte Carlo method}

The classic Monte Carlo simulation method consists in generating $x$-realization of a random vector $\mathbf{X}$ in accordance with the total density of a probability distribution $f_{x}(\mathbf{x})$, and then checking whether the given implementation lies in the safe area or in the failure area. The number of 'hits' in the area of failure in relation to the total number of simulations is the estimator of the probability of failure. The above idea can be expressed by defining the characteristic function of the set (the area of failure) as

$$
X_{\Omega_{f}}(\mathbf{x})=\left\{\begin{array}{lll}
1 & \text { if } & \mathbf{x} \in \Omega_{f} \\
0 & \text { if } & \mathbf{x} \notin \Omega_{f}
\end{array}\right.
$$

$X_{\Omega_{f}}(\mathbf{x})$ is therefore a random variable with a two-point distribution

$$
P\left[X_{\Omega_{f}}(\mathbf{X})=1\right]=P_{f} \quad P\left[X_{\Omega_{f}}(\mathbf{X})=0\right]=1-P_{f}
$$

where $P_{f}=P\left[\mathbf{X} \in \Omega_{f}\right]$. The mean value and the variance $X_{\Omega_{f}}(\mathbf{x})$ have the form

$$
\begin{aligned}
& X_{\Omega_{f}}^{0}(\mathbf{X})=E\left[X_{\Omega_{f}}(\mathbf{x})\right]=1 \cdot P_{f}+0 \cdot\left(1-P_{f}\right)=P_{f} \\
& \operatorname{Var}\left[X_{\Omega_{f}}(\mathbf{X})\right]=E\left[\left(X_{\Omega_{f}}(\mathbf{X})\right)^{2}\right]-\left(E\left[X_{\Omega_{f}}(\mathbf{X})\right]\right)^{2}=P_{f}-P_{f}^{2}=P_{f}\left(1-P_{f}\right)
\end{aligned}
$$

In the Monte Carlo method, the estimator of the mean value of the characteristic of the set, has the form

$$
\widetilde{X}_{\Omega_{f}}^{0}=\frac{1}{K} \sum_{k=1}^{K} X_{\Omega_{f}}\left(\mathbf{X}_{k}\right)=\widetilde{P_{f}}
$$


where $\mathbf{X}_{k}$ are independent random vectors with a probability distribution defined by the density function $f_{x}(\mathbf{x})$, and $K$ is the number of simulations.

The average value and variance of the estimator is given as

$$
\begin{aligned}
& \widetilde{P_{f}^{0}}=E\left[\widetilde{P_{f}}\right]=\frac{1}{K} \sum_{k=1}^{K} X_{\Omega_{f}}^{0}\left(\mathbf{X}_{k}\right)=\frac{1}{K} K P_{f}=\widetilde{P_{f}} \\
& \sigma_{\widetilde{P_{f}}}^{2}=\operatorname{Var}\left[\widetilde{P_{f}}\right]=\frac{1}{K^{2}} \sum_{k=1}^{K} \operatorname{Var}\left[X_{\Omega_{f}}\left(\mathbf{X}_{k}\right)\right]=\frac{1}{K^{2}} K P_{f}\left(1-P_{f}\right)=\frac{1}{K} P_{f}\left(1-P_{f}\right)
\end{aligned}
$$

The variation coefficient of the estimator is

$$
v_{\widetilde{P_{f}}}=\frac{\sigma_{\widetilde{P_{f}}}}{\widetilde{P_{f}^{0}}}=\sqrt{\frac{1-P_{f}}{K P_{f}}}
$$

The above formula shows how the variation coefficient of 0.1 for the expected probability of failure was obtained. In real structures, the coefficient ranges from $10^{-7}$ to $10^{-4}$ and requires $K=10^{6}-10^{9}$ simulations.

\section{Numerical results and discussion}

\subsection{Geometry}

A mesh of a single-layer dome consisting of 37 nodes and 84 elements is illustrated in Fig. 1. The dome geometry is shown in Table 1.

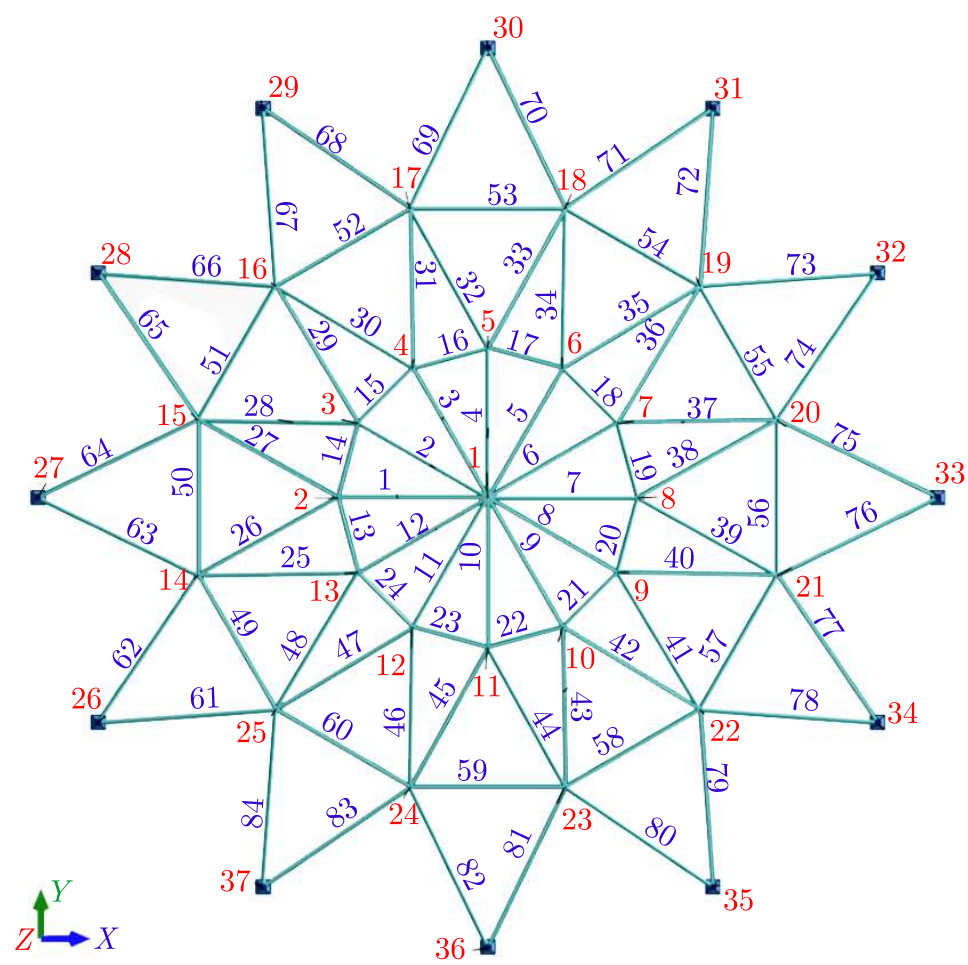

Fig. 1. Mesh of the dome elements

The structure shown above has been analysed in two stages. The first, deterministic stage, is directed to finding coordinates of the limit point on the load-displacement path using the FEM Abaqus software. These coordinates are necessary to determine the parameters of the 
Table 1. Geometry of the dome

\begin{tabular}{|c|c|c|c|c|c|c|c|}
\hline $\begin{array}{c}\text { No. of } \\
\text { node }\end{array}$ & $x[\mathrm{~m}]$ & $y[\mathrm{~m}]$ & $z[\mathrm{~m}]$ & $\begin{array}{c}\text { No. of } \\
\text { node }\end{array}$ & $x[\mathrm{~m}]$ & $y[\mathrm{~m}]$ & $z[\mathrm{~m}]$ \\
\hline \hline 1 & 14.489 & 14.489 & 0.900 & 20 & 21.733 & 16.430 & 0.400 \\
\hline 2 & 10.739 & 14.489 & 0.750 & 21 & 21.733 & 12.548 & 0.400 \\
\hline 3 & 11.241 & 16.364 & 0.750 & 22 & 19.792 & 9.186 & 0.400 \\
\hline 4 & 12.614 & 17.736 & 0.750 & 23 & 16.430 & 7.244 & 0.400 \\
\hline 5 & 14.489 & 18.239 & 0.750 & 24 & 12.548 & 7.244 & 0.400 \\
\hline 6 & 16.364 & 17.736 & 0.750 & 25 & 9.186 & 9.186 & 0.400 \\
\hline 7 & 17.736 & 16.364 & 0.750 & 26 & 4.746 & 8.864 & 0.0 \\
\hline 8 & 18.239 & 14.489 & 0.750 & 27 & 3.239 & 14.489 & 0.0 \\
\hline 9 & 17.736 & 12.614 & 0.750 & 28 & 4.746 & 20.114 & 0.0 \\
\hline 10 & 16.364 & 11.241 & 0.750 & 29 & 8.864 & 24.232 & 0.0 \\
\hline 11 & 14.489 & 10.739 & 0.750 & 30 & 14.489 & 25.739 & 0.0 \\
\hline 12 & 12.614 & 11.241 & 0.750 & 31 & 20.114 & 24.232 & 0.0 \\
\hline 13 & 11.241 & 12.614 & 0.750 & 32 & 24.232 & 20.114 & 0.0 \\
\hline 14 & 7.244 & 12.548 & 0.400 & 33 & 25.739 & 14.489 & 0.0 \\
\hline 15 & 7.244 & 16.430 & 0.400 & 34 & 24.232 & 8.864 & 0.0 \\
\hline 16 & 9.186 & 19.792 & 0.400 & 35 & 20.114 & 4.746 & 0.0 \\
\hline 17 & 12.548 & 21.733 & 0.400 & 36 & 14.489 & 3.239 & 0.0 \\
\hline 18 & 16.430 & 21.733 & 0.400 & 37 & 8.864 & 4.746 & 0.0 \\
\hline 19 & 19.792 & 19.792 & 0.400 & & & & \\
& & \multicolumn{1}{|l}{}
\end{tabular}

limit function in reliability analysis. The second step involves combining the Numpress Explore and Abaqus programs. This analysis makes it possible to estimate the reliability index.

\subsection{STAGE I - Static - strength analysis}

\subsubsection{Step $1-L A-$ Linear analysis}

In the first step, linear analysis of a steel single-layer dome modelled with frame elements and loaded with $P=10 \mathrm{kN}$ in each node was performed. On the basis of the calculations made, the cross-section of the elements was determined as a steel pipe RO101.6x6 with the yield point $f_{y}=23.5 \mathrm{kN} / \mathrm{cm}^{2}$ and Young's modulus $E=21000 \mathrm{kN} / \mathrm{cm}^{2}$. Elements from 61 to 84 are the most stressed. Table 2 shows the values of internal forces, load capacity and limit values of displacements for element No. 84 and node No. 25. As regards the selection of cross-sections, it was decided by the stability condition of the bent and compressed element.

\subsubsection{Step 2-LBA - Linear Buckling Analysis}

In the second step, the structure under consideration underwent linear buckling analysis. The structure was loaded with $\mu P$ load in each node $(P=10 \mathrm{kN})$. Figure 2 shows deformation of the structure. The critical load multiplier $\mu_{c r}$ was equal to 1.465. According to PN-EN 19931.1/5.2.2 (5) B, if the critical load multiplier $\mu_{c r}<3.0$, a more accurate second order analysis (GNA) is necessary for the structure.

\subsubsection{Step 3-GNA - Geometric Nonlinear Analysis for $P=10 \mathrm{kN}$}

In the third step, a geometrically nonlinear static analysis of the considered structure was carried out. In the shallow bar dome modelled with frame elements, internal forces, strength 
Table 2. Values of the internal forces, capacity of the most stressed element of the structure (element No. 84), and the maximum horizontal and vertical displacement of node No. 25

\begin{tabular}{|l|c|}
\hline \multicolumn{1}{|c|}{ Internal force/capacity } & Value \\
\hline \hline$N_{E d}[\mathrm{kN}]-$ axial force & 113.156 \\
\hline$N_{c, R d}[\mathrm{kN}]$ - design capacity of section under uniform compression & 423.00 \\
\hline$N_{b, R d}[\mathrm{kN}]$ - design buckling resistance of compressed element & 176.097 \\
\hline$M_{y, E d, \max }[\mathrm{kNm}]$ - design bending moment with respect to $y$ - $y$ axis & 122.83 \\
\hline$M_{y, c, R d}[\mathrm{kNm}]$ - design bending resistance with respect to $y$ - $y$ axis & 1290.34 \\
\hline$M_{z, E d, \max }[\mathrm{kNm}]$ - design bending moment with respect to $z$ - $z$ axis & -2.98 \\
\hline$M_{z, c, R d}[\mathrm{kNm}]-$ design bending resistance with respect to $z-z$ axis & 1290.34 \\
\hline Strength utilisation $[\%]$ & 77 \\
\hline Maximum vertical displacement $[\mathrm{mm}]-$ for node 25 & 30.61 \\
\hline Allowable vertical displacement $[\mathrm{mm}]-d / 300$ & 75.00 \\
\hline Maximum horizontal displacement $[\mathrm{mm}]-$ for node 25 & 1.32 \\
\hline Allowable horizontal displacement $[\mathrm{mm}]-h / 150$ & 6.00 \\
\hline
\end{tabular}

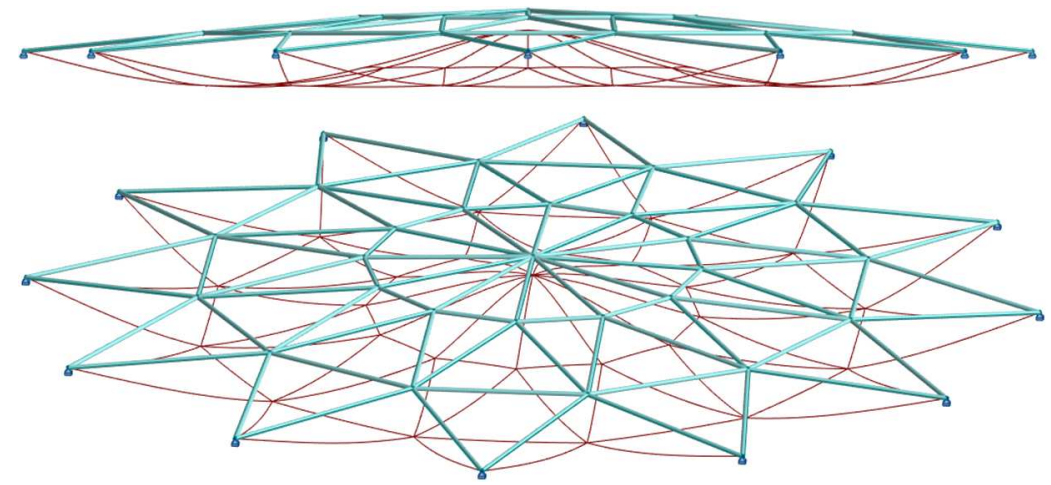

Fig. 2. Ribbed dome deformation

Table 3. Values of the internal forces, capacity of the most stressed element of the structure (element No. 84), and the maximum horizontal and vertical displacement of node 25

\begin{tabular}{|l|c|}
\hline \multicolumn{1}{|c|}{ Internal force/capacity } & Value \\
\hline \hline$N_{E d}[\mathrm{kN}]-$ axial force & 125.80 \\
\hline$N_{c, R d}[\mathrm{kN}]$ - design capacity of section under uniform compression & 423.00 \\
\hline$N_{b, R d}[\mathrm{kN}]-$ design buckling resistance of compressed element & 179.097 \\
\hline$M_{y, E d, \max }[\mathrm{kNm}]$ - design bending moment with respect to $y$ - $y$ axis & 162.60 \\
\hline$M_{y, c, R d}[\mathrm{kNm}]-$ design bending resistance with respect to $y$ - $y$ axis & 1290.34 \\
\hline$M_{z, E d, \max }[\mathrm{kNm}]$ - design bending moment with respect to $z$ - $z$ axis & -5.61 \\
\hline$M_{z, c, R d}[\mathrm{kNm}]-$ design bending resistance with respect to $z-z$ axis & 1290.34 \\
\hline Strength utilisation [\%] & 90 \\
\hline Maximum vertical displacement $[\mathrm{mm}]-$ for node 25 & 45.38 \\
\hline Allowable vertical displacement [mm] $-d / 300$ & 75.00 \\
\hline Maximum horizontal displacement [mm] - for node 25 & 2.02 \\
\hline Allowable horizontal displacement $[\mathrm{mm}]-h / 150$ & 6.00 \\
\hline
\end{tabular}

utilisation and displacements were verified when the force $P$ was equal to $10 \mathrm{kN}$. Table 3 shows values of internal forces, strength utilisation and displacements for the most stressed element (No. 84) and node No. 25. 


\subsubsection{Step 4-GNA - Geometric Nonlinear Analysis for $P=11.10 \mathrm{kN}$}

In the last step, the behaviour of the structure was analysed in the case of structural load with the maximum value obtained in geometrically nonlinear analysis. The structure was loaded with a one-parameter load $\mu P$ at each node, and the value of the critical load multiplier was $\mu_{c r}=1.11, P=10 \mathrm{kN}$. The analysis was carried out using the Simulia Abaqus software, and the Riks analysis algorithm. Table 4 shows the values of internal forces, strength utilisation in element No. 84 and the displacement of node No. 25 in the case under consideration.

Table 4. Values of the internal forces, capacity of the most stressed element of the structure (element No. 84), and the maximum horizontal and vertical displacement of node 25

\begin{tabular}{|l|c|}
\hline \multicolumn{1}{|c|}{ Internal force/capacity } & Value \\
\hline \hline$N_{E d}[\mathrm{kN}]$ - axial force & 132.816 \\
\hline$N_{c, R d}[\mathrm{kN}]$ - design capacity of section under uniform compression & 423.00 \\
\hline$N_{b, R d}[\mathrm{kN}]$ - design buckling resistance of compressed element & 183.19 \\
\hline$M_{y, E d, \max }[\mathrm{kNm}]$ - design bending moment with respect to $y$ - $y$ axis & 122.83 \\
\hline$M_{y, c, R d}[\mathrm{kNm}]-$ design bending resistance with respect to $y$ - $y$ axis & 1290.34 \\
\hline$M_{z, E d, \max }[\mathrm{kNm}]$ - design bending moment with respect to $z$ - $z$ axis & -6.66 \\
\hline$M_{z, c, R d}[\mathrm{kNm}]$ - design bending resistance with respect to $z$ - $z$ axis & 1290.34 \\
\hline Strength utilisation [\%] & 96 \\
\hline Maximum vertical displacement $[\mathrm{mm}]-$ for node 25 & 49.69 \\
\hline Allowable vertical displacement $[\mathrm{mm}]-d / 300$ & 75.00 \\
\hline Maximum horizontal displacement $[\mathrm{mm}]-$ for node 25 & 1.848 \\
\hline Allowable horizontal displacement $[\mathrm{mm}]-h / 150$ & 6.00 \\
\hline
\end{tabular}

The first stage of structural analysis is the verification of the steel shallow dome modelled with frame elements (Element B32 in Abaqus) in terms of statics and strength. In the analysis, it was shown that for the considered structure it is necessary to conduct a geometrically nonlinear analysis. The strength utilisation of the structure in the first step, i.e. linear static analysis, was $77 \%$, while for the GNA analysis, it increased to $90 \%$. The stresses in bars, for the maximum load value of the structure in geometrically non-linear static analysis, did not exceed $96 \%$, which indicates that the global stability loss is a decisive mode of stability failure. The allowable vertical displacement value (deflections) determined on the basis of EC-1993-1-1 is $7.5 \mathrm{~cm}$. The GNA analysis showed, however, that for the load value of $P_{c r}=11.10 \mathrm{kN}$, the maximum displacement of the node in the structure is $4.969 \mathrm{~cm}$. This means that the determined value according to Eurocode of the allowable displacement is almost $51 \%$ greater than the maximum value of the displacement obtained from a more accurate structural analysis - GNA.

\subsection{STAGE II - Probabilistic analysis with the Monte Carlo method}

Based on the outcomes of analysis presented in Sections 4.2.1-4.2.4, reliability analysis was carried out. Two types of this analysis were distinguished:

- Analysis 1 - reliability analysis of the frame element (steel pipe RO 101.6x6)

- Analysis 2 - reliability analysis of the entire structure.

In both cases, random variables are: $R$ - external radius of the cross-section and $t$ - wall thickness of the cross-section. The third random variable in the case reliability analysis of the frame element is $f_{y}$ - the yield point of steel, while in the case of the structural reliability analysis it is $E$ - Young's modulus. The values of all random variables are listed in Table 5. 
Table 5. The values of random variables in all types of reliability analysis

\begin{tabular}{|c|c|c|c|c|c|c|}
\hline \multirow{2}{*}{$\begin{array}{c}\text { Random } \\
\text { variable } \\
X_{i}\end{array}$} & \multicolumn{2}{|c|}{ Analysis 1 - frame element } & \multicolumn{3}{c|}{ Analysis 2 - structure } \\
\cline { 2 - 7 } & $\begin{array}{c}\text { Mean } \\
\text { value }\end{array}$ & $\begin{array}{c}\text { Standard } \\
\text { deviation }\end{array}$ & $\begin{array}{c}\text { Variation } \\
\text { coefficient }\end{array}$ & $\begin{array}{c}\text { Mean } \\
\text { value }\end{array}$ & $\begin{array}{c}\text { Standard } \\
\text { deviation }\end{array}$ & $\begin{array}{c}\text { Variation } \\
\text { coefficient }\end{array}$ \\
\hline \hline$R[\mathrm{~cm}]$ & 5.08 & 0.2032 & $4 \%$ & 5.08 & 0.2032 & $4 \%$ \\
\hline$t[\mathrm{~cm}]$ & 0.60 & 0.0024 & $4 \%$ & 0.60 & 0.0024 & $4 \%$ \\
\hline$f_{y}\left[\mathrm{kN} / \mathrm{cm}^{2}\right]$ & 23.50 & 1.4100 & $6 \%$ & - & - & - \\
\hline$E\left[\mathrm{kN} / \mathrm{cm}^{2}\right]$ & - & - & - & 21000 & 1260 & $6 \%$ \\
\hline
\end{tabular}

In the case of reliability analysis of the frame element, the limit function was defined as the condition of not exceeding the capacity due to stability of the bar, simultaneously compressed and bent. The general version of the condition is as follows

$$
f_{b}=1-\frac{N}{N_{b, R d}}-\frac{k_{z y} M_{y}}{\chi M_{y, R k}}
$$

where: $N_{b, R d}[\mathrm{kN}]$ - buckling resistance of the compressed element, $M_{y, R k}[\mathrm{kNm}]$ - bending resistance with respect to $y$ - $y$ axis, $\chi$ - buckling coefficient, $k_{z y}$-interaction coefficient acc. PN-EN 1993-1-1.

For the needs of the analysis, the condition was developed using the following relationships

$$
\begin{aligned}
& N_{b, R d}=A \frac{f_{y}}{\gamma_{M 1}} \quad A=\pi\left(2 R t-t^{2}\right) \\
& M_{y, R k}=W_{p l} \frac{f_{y}}{\gamma_{M 1}} \quad W_{p l}=4 \frac{3 R^{2} t-3 R t^{2}+t^{3}}{3}
\end{aligned}
$$

The final version of the limit function takes the following form

$$
f_{b}=1-\frac{N_{E d}}{\chi \Pi\left(2 R t-t^{2}\right) f_{y}}-\frac{3 k_{z y} M_{y}}{4\left(3 R^{2} t-3 R t^{2}+t^{3}\right) f_{y}}
$$

In the case of reliability analysis of the entire structure, the limit function is defined as a condition of non-exceedance of the maximum vertical displacement obtained in the nonlinear geometric analysis

$$
f_{s}=1-\frac{w(x)}{w_{\max }}=1-\frac{w(x)}{4.969}
$$

where: $w(x)$ - vertical displacement for node $25, w_{\max }$ - maximum vertical displacement for node 25 obtained in the nonlinear geometric analysis [cm] (Table 4).

The reliability analysis was carried out using the NumpressExplore program created at IPPT PAN in Warsaw (http://www.numpress.ippt.pan.pl/, Kowalczyk et al., 2014; Lógó et al., 2011). The determination of the reliability index in both analyses differed significantly.

In the case of Analysis 1, i.e. determination of the reliability index for the most stressed element of the structure, the explicit form of the limit function expressed by formula (4.3) was used. The calculations were carried out in accordance with the algorithm shown in Fig. 3.

For the sake of Analysis 2, it was necessary to combine the NumpressExplore program with the numerical analysis program Simulia Abaqus. In that case, the implicit form of the limit function was used, as described by Eq. (4.4). NumpressExplore made it possible to define two types of random variables, namely, basic and external ones. The external variables were 


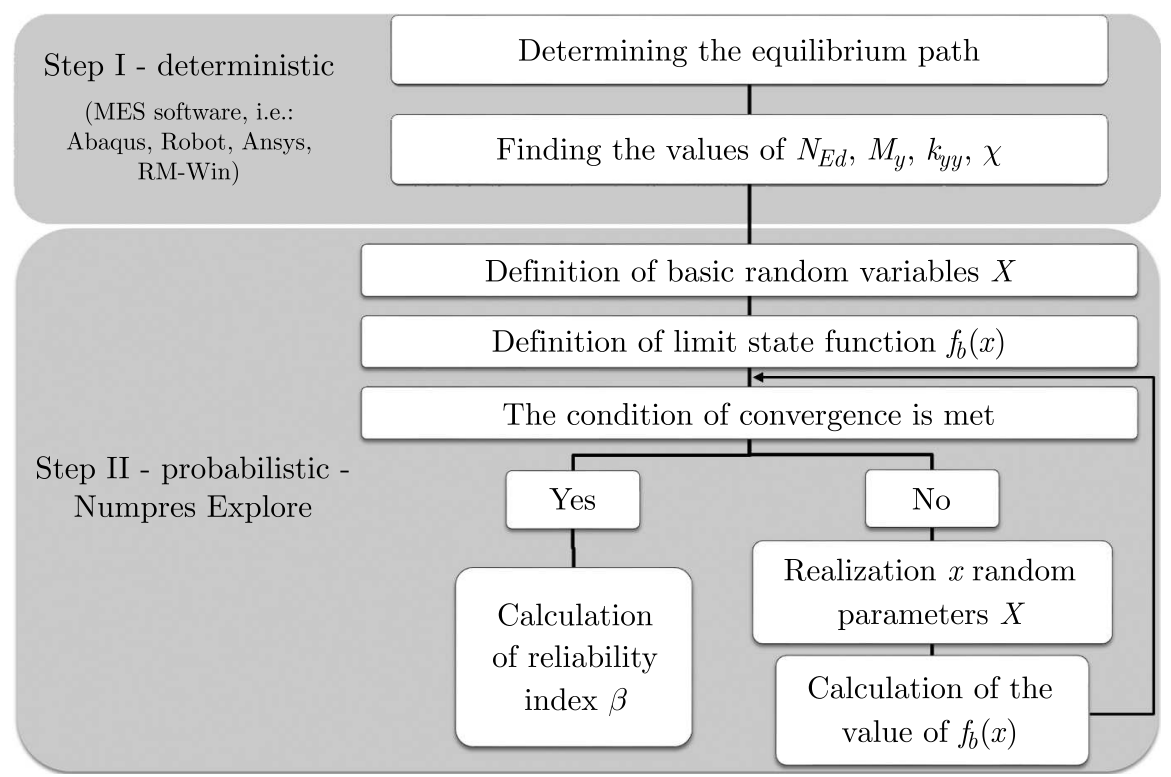

Fig. 3. Procedure of the analysis for the explicit limit state function

implicit functions of basic random variables, the values of which were obtained with the Abaqus software. The values of external variables were read from the text files that contained the results of computations with the Abaqus software. The next step involved the introduction of the limit function formula, using the standard mathematical notation as a dependence on basic and external random variables. NumpressExplore software communicated with the Abaqus software to perform analysis. The latter was used to compute the values necessary to define the limit function for subsequent sets of random variables. Next, the reliability analysis method was chosen and computations began. The task ended with generation of information that contained the value of the reliability index. In Fig. 4, the procedure of the analysis algorithm for the implicit limit state function is shown.

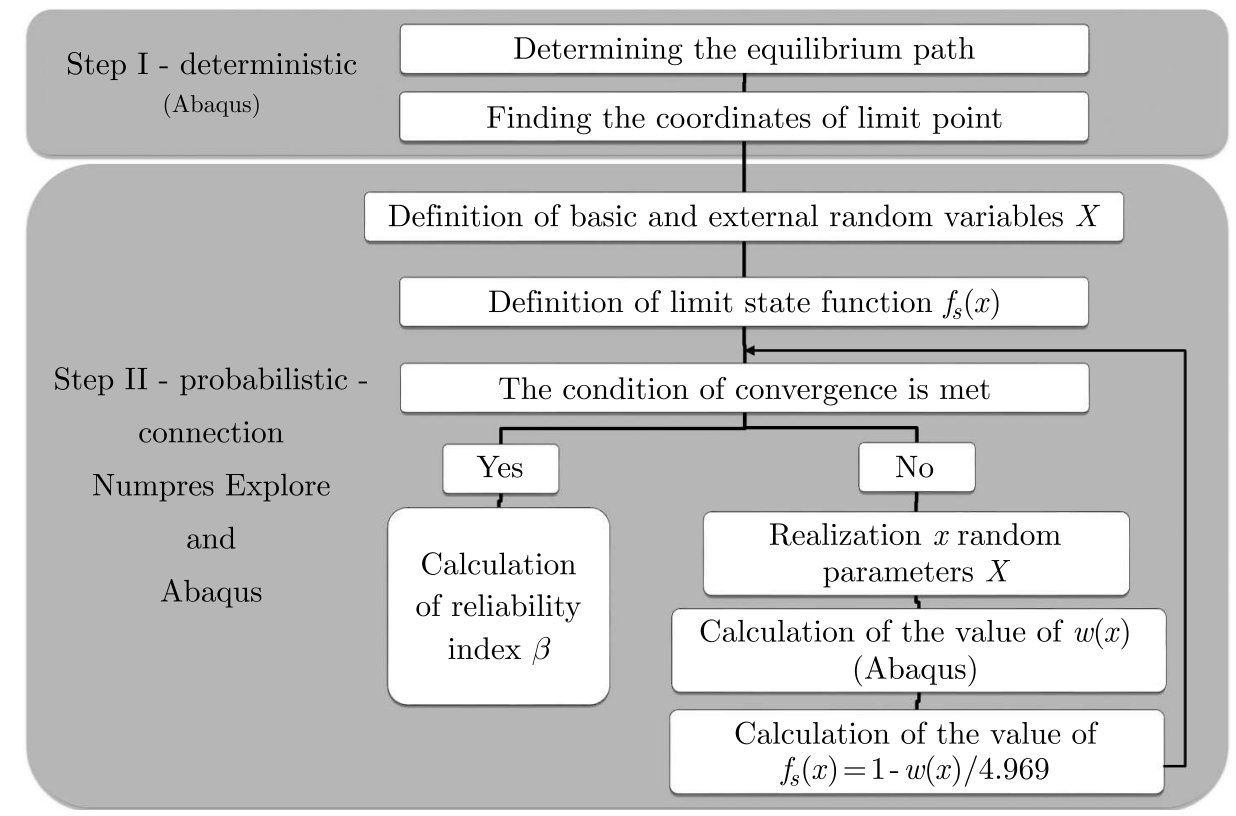

Fig. 4. Procedure of the analysis for the implicit limit state function

Table 6 shows the values of the reliability index for both types of analyses. 
Table 6. The values of the reliability index $\beta$ in both types of the reliability analysis

\begin{tabular}{|c|c|c|c|}
\hline $\begin{array}{c}\text { Load } \mu P \\
{[\mathrm{kN}]}\end{array}$ & $\begin{array}{c}\text { Displacement } \\
w[\mathrm{~cm}]\end{array}$ & $\begin{array}{c}\text { Analysis } 1-\text { frame element } \\
\beta\end{array}$ & $\begin{array}{c}\text { Analysis 2 - structure } \\
\beta\end{array}$ \\
\hline \hline 8.095 & 3.078 & 4.892 & 3.156 \\
\hline 8.762 & 3.420 & 4.013 & 2.461 \\
\hline 9.392 & 3.767 & 3.147 & 1.737 \\
\hline 9.984 & 4.133 & 2.295 & 1.083 \\
\hline 10.57 & 4.538 & 1.396 & 0.457 \\
\hline
\end{tabular}

\section{Conclusions}

In the study, a single-layer dome modelled with frame elements was discussed. Due to the rise-to-span ratio $h / d=0.04$, this is a shallow dome. On the basis of the first stage of the analysis, it was shown that the critical load multiplier in the linear bifurcation analysis (LBA) was 1.465. For frame structures, when the critical load multiplier is not greater than 3, PN-EN-1993 standard recommends execution of nonlinear geometric analysis GNA. The nonlinear geometric analysis showed that the limit load for this structure was $11.10 \mathrm{kN}$, and the maximum strength utilisation of the bar was $96 \%$. The decisive mode of stability loss is the global stability failure due to node snap-through. The summary of calculations is provided in Table 7 .

Table 7. The summary of calculations of the first stage.

\begin{tabular}{|c|c|c|c|}
\hline Internal force/capacity & $\begin{array}{c}\text { LA } \\
\mu=1.000\end{array}$ & $\begin{array}{c}\text { GNA } \\
\mu=1.000\end{array}$ & $\begin{array}{c}\text { GNA } \\
\mu_{c r}=1.110\end{array}$ \\
\hline$N_{E d}[\mathrm{kN}]$ & 113.156 & 125.800 & 132.816 \\
\hline$N_{c, R d}[\mathrm{kN}]$ & 423.000 & 423.000 & 423.000 \\
\hline$N_{b, R d}[\mathrm{kN}]$ & 176.097 & 176.097 & 176.097 \\
\hline$M_{y, E d, \max }[\mathrm{kNm}]$ & 122.830 & 162.600 & 183.190 \\
\hline$M_{y, c, R d}[\mathrm{kNm}]$ & 1290.340 & 1290.340 & 1290.340 \\
\hline$M_{z, E d, \max }[\mathrm{kNm}]$ & -2.980 & -5.610 & -6.660 \\
\hline$M_{z, c, R d}[\mathrm{kNm}]$ & 1290.340 & 1290.340 & 1290.340 \\
\hline Strength utilisation [\%] & 77 & 90 & 96 \\
\hline Max. vertical disp. $[\mathrm{mm}]$ & 30.610 & 45.380 & 49.690 \\
\hline Allowable vertical disp. $[\mathrm{mm}]$ & 75.000 & 75.000 & 75.000 \\
\hline Maximum horizontal disp. [mm] & 1.320 & 2.020 & 1.848 \\
\hline Allowable horizontal disp. $[\mathrm{mm}]$ & 6.000 & 6.000 & 6.000 \\
\hline
\end{tabular}

In the second stage, the reliability of both the single structural frame element and the entire dome was verified. The results from this stage are listed in Table 6 . The analysis was carried out for several different values of the structure loading. The load values for which the reliability index was calculated were determined in the incremental nonlinear static analysis (Riks) process. It was observed that the highest reliability index value in both cases was obtained for a load of $8.095 \mathrm{kN}$. The lowest recorded value of the reliability index in the case of Analysis 1 was 1.396 for the load $P=10.57 \mathrm{kN}$. With respect to the reliability analysis of the entire structure, it was observed that the lowest value of the reliability index was recorded for the same load value as in the case of Analysis 1 , and was $\beta=0.457$. This value is only about $32.7 \%$ of the value from Analysis 1.

The results obtained can be directly compared with the values adopted in PN-EN 1990 standard. In accordance with the above standard, in the case of verification of the ultimate limit states for the most popular RC2 design situation, the value of the reliability index is $\beta=3.8$. 
When the serviceability limit states are verified, this value is $\beta=1.5$ (PN-EN 1990). In this study, the reliability analysis for the ultimate limit states was presented in Analysis 1, i.e. the analysis of the reliability of the most stressed bar in the structure. The data in Table 6 indicate the standard value of the reliability index was not exceeded for the structure load below $P=8.762 \mathrm{kN}$. The dashed line in Fig. 5 indicates the value of the load multiplier $(\mu=0.892)$ for which the reliability index $\beta=3.8$.

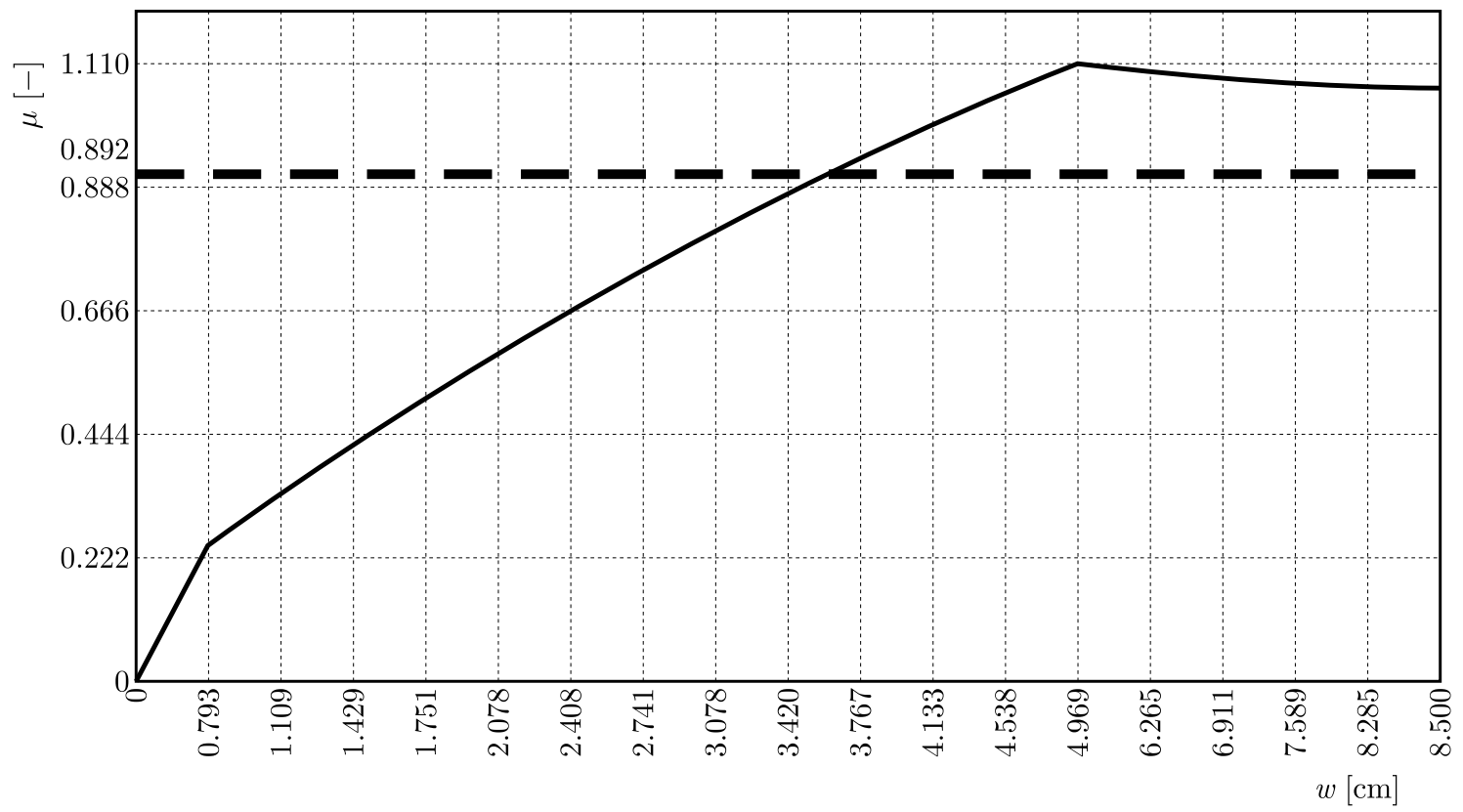

Fig. 5. Load displacement path (ultimate limit state, $\mathrm{RC} 2, \beta=3.8$ )

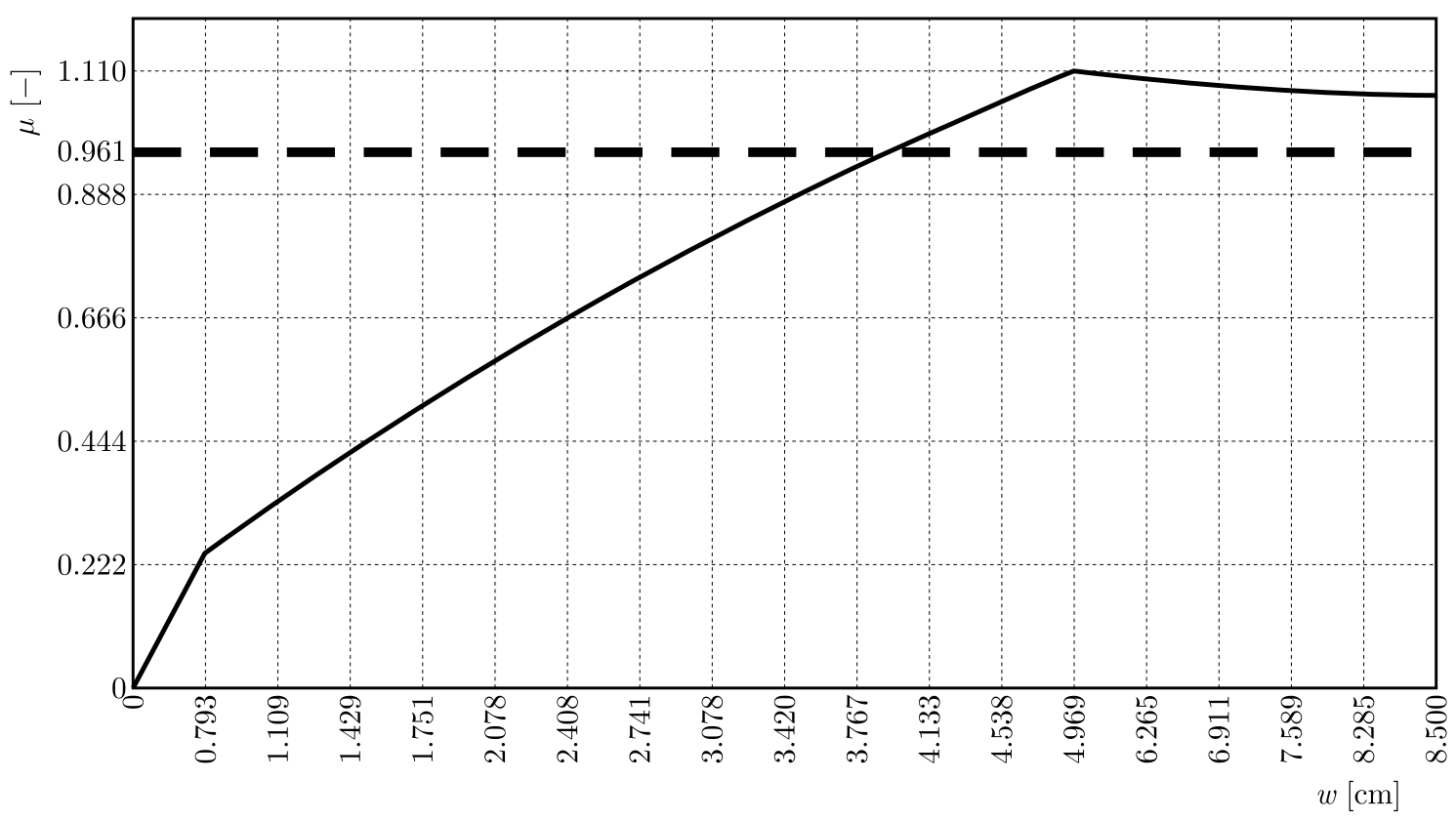

Fig. 6. Load displacement path (serviceability limit state, $\mathrm{RC} 2, \beta=1.5$ )

Analysis 2, the analysis of the reliability of the entire structure, represents a situation in which the obtained values of the reliability index can be compared with the value of the reliability index adopted in the Eurocode for serviceability limit states (RC2 situation). Table 6 shows that the exceedance of the limit value $\beta=1.5$ occurs when the displacement is greater than $3.767 \mathrm{~cm}$. 
That happens at the moment when the load is equal to $P=9.392 \mathrm{kN}$. The dashed line in Fig. 6 indicates the value of the load multiplier $(\mu=0.961)$ for which the reliability index $\beta=1.5$.

\section{References}

1. Chodor L., 2019, Mesh dome, http://www.chodor-projekt.net/encyclopedia/kopula-siatkowa/ (available online 14.11.2019)

2. GiżEjowski M., ZıóŁko J. (Edit.), 2010, General Construction, Steel Constructions of Buildings. Design According to Eurocodes with Examples of Calculations (in Polish), Volume 5, Arkady, Warsaw

3. Kacprzyk Z., PawŁowska B., 1999, Generator of spatial structures (in Polish), Computer Methods in Civil Engineering, 5, 19-33

4. Kato S., Мutoh I., Shomura M., 1998, Collapse of semi-rigidly jointed reticulated domes with initial geometrical imperfections, Journal of Constructional Steel Research, 48, 2-3, 145-168

5. KLeiber M., 1982, Some results in the numerical analysis of structural instabilities. Part 1 Statics, Engineering Transactions, 30, 327-352

6. Kowalczyk P., Rojek J., Stocki R., Bednarek T., Tauzowski P., Lasota R., Lumelskyy D., WAWRZYK K., 2014, NUMPRESS - integrated computer system for analysis and optimization of industrial sheet metal forming processes, Hutnik - Wiadomości Hutnicze, ISSN: 1230-3534, 81, $1,56-63$

7. Liu H., Zhang W., YuAn H., 2016, Structural stability analysis of single-layer reticulated shells with stochastic imperfection, Engineering Structures, 124, 473-479

8. Lógó J., Movahedi Rad M., Knabel J., Tauzowski P., 2011, Reliability based design of frames with limited residual strain energy capacity, Periodica Polytechnica Civil Engineering, 55, $1,13-20$

9. Luca B., Sassone M., Venuti F., 2016, Effects of the equivalent geometric nodal imperfection on the stability of single layer grid shells, Engineering Structures, 112, 184-199

10. Marcinowski J., 2017, Stability of Elastic Structures (in Polish), Dolnoślaskie Wydawnictwo Edukacyjne

11. Numpress Computer System, http://www.numpress.ippt.pan.pl/ (available online 14.11.2019)

12. Mochocki W., Radoń U., 2019, Analysis of basic failure scenarios of a truss tower in a probabilistic approach, Applied Sciences, 9, 13, 2662, 417-427

13. PN-EN 1990. Eurocode 0: Basis of structural design

14. PN-EN 1993-1-1. Eurocode 3: Design of steel structures. Part 1-1: General rules and rules for buildings

15. Rubinstein R.Y., 1981, Simulation and the Monte Carlo Method, Wiley

16. Thompson J.M.T, Hunt G.W., 1973, A General Theory of Elastic Stability, Wiley \& Sons

17. Waszczyszyn Z., Cichoń Cz., Radwańska M., 1994, Stability of Structures by Finite Element Methods, Elsevier

18. Zabojszcza P., Radoń U., 2019a, Effect of increased density on nodes in geodesic dome on its critical load capacity, IOP Conference series - Materials Science and Engineering, 471, DOI: 10.1088/1757-899X/471/5/052051

19. Zabojszcza P., RAdoń U., 2019b, The impact of node location imperfections on the reliability of single-layer steel domes, Applied Sciences, 9, 2742 